\title{
Groundwater arsenic removal by coagulation using ferric(III) sulfate and polyferric sulfate: A comparative and mechanistic study
}

\author{
Jinli Cui ${ }^{1}$, Chuanyong Jing ${ }^{1, *}$, Dongsheng Che ${ }^{2}$, Jianfeng Zhang ${ }^{2, *}$, Shuxuan Duan ${ }^{3}$ \\ 1. State Key Laboratory of Environmental Chemistry and Ecotoxicology, Research Center for Eco-Environmental Sciences, Chinese Academy of \\ Sciences, Beijing 100085, China. E-mail: jlcuit@163.com \\ 2. School of Environmental and Municipal Engineering, Xi'an University of Architecture and Technology, Xi'an 710055, China \\ 3. State Key Laboratory of Environmental Aquatic Chemistry, Research Center for Eco-Environmental Sciences, Chinese Academy of Sciences, \\ Beijing 100085, China
}

\section{A R T I C L E I N F O}

Article history:

Received 10 September 2014

Revised 10 October 2014

Accepted 17 October 2014

Available online 2 April 2015

Keywords:

Groundwater As removal

Ferric(III) sulfate (FS)

Polyferric sulfate (PFS)

Coagulation

EXAFS

Leaching

\begin{abstract}
A B S T R A C T
Elevated arsenic (As) in groundwater poses a great threat to human health. Coagulation using mono- and poly-Fe salts is becoming one of the most cost-effective processes for groundwater As removal. However, a limitation comes from insufficient understanding of the As removal mechanism from groundwater matrices in the coagulation process, which is critical for groundwater treatment and residual solid disposal. Here, we overcame this hurdle by utilizing microscopic techniques to explore molecular As surface complexes on the freshly formed Fe flocs and compared ferric(III) sulfate (FS) and polyferric sulfate (PFS) performance, and finally provided a practical solution in As-geogenic areas. FS and PFS exhibited a similar As removal efficiency in coagulation and coagulation/filtration in a two-bucket system using $5 \mathrm{mg} / \mathrm{L} \mathrm{Ca}(\mathrm{ClO})_{2}$. By using the two-bucket system combining coagulation and sand filtration, $500 \mathrm{~L}$ of As-safe water $(<10 \mu \mathrm{g} / \mathrm{L})$ was achieved during five treatment cycles by washing the sand layer after each cycle. Fe k-edge X-ray absorption near-edge structure (XANES) and As k-edge extended X-ray absorption fine structure (EXAFS) analysis of the solid residue indicated that As formed a bidentate binuclear complex on ferrihydrite, with no observation of scorodite or poorly-crystalline ferric arsenate. Such a stable surface complex is beneficial for As immobilization in the solid residue, as confirmed by the achievement of much lower leachate As $(0.9 \mu \mathrm{g} / \mathrm{L}-0.487 \mathrm{mg} / \mathrm{L})$ than the US EPA regulatory limit ( $5 \mathrm{mg} / \mathrm{L}$ ). Finally, PFS is superior to FS because of its lower dose, much lower solid residue, and lower cost for As-safe drinking water.

(C) 2015 The Research Center for Eco-Environmental Sciences, Chinese Academy of Sciences.
\end{abstract} Published by Elsevier B.V.

\section{Introduction}

Arsenic (As) in groundwater is a worldwide crisis, which affects the health of over 100 million people (Fendorf et al., 2010;
Rodriguez-Lado et al., 2013). The As-contaminated groundwater usually is the sole source of drinking water for local residents in As-geogenic areas (Cui et al., 2013; Rodriguez-Lado et al., 2013). In these areas, widespread symptoms of skin diseases and cancers

\footnotetext{
* Corresponding authors. E-mail: cyjing@rcees.ac.cn (Chuanyong Jing), zhangjianfeng@xauat.edu.cn (Jianfeng Zhang).
} 
of the liver, bladder, and lung are often observed due to chronic As exposure (Chen and Ahsan, 2004; Wasserman et al., 2004). Thus it is urgent to treat the groundwater to supply safe drinking water.

Coagulation/filtration using iron ( $\mathrm{Fe}$ ) or aluminum (Al) salts is the most effective technology for groundwater As removal (Davis and Edwards, 2014; Du et al., 2014; US EPA, 2003). Coagulated As removal usually employs Fe salts rather than $\mathrm{Al}$ salts, as Fe salts have been demonstrated to have better As removal performance due to their higher adsorption site density (Fan et al., 2003). Recently, a prehydrolyzed polyferric sulfate was developed by optimizing multinuclear hydroxyl complexes with various charges, which showed superior coagulation efficiency compared to ferric salts (Cheng, 2002; Liang et al., 2009). Since its development, a limited number of studies were conducted on the comparison between mono- and poly-Fe salts for the As removal process (Cheng, 2002; Fan et al., 2003; Liang et al., 2009). These comparative studies have always been performed in simulated water on the macroscopic level, including coagulation dose, $\mathrm{pH}$, and the initial As concentration. However, this macroscopic evidence contributes little to the understanding of their comparative coagulation processes and As removal mechanisms in groundwater. Furthermore, groundwater matrices exhibit complex characteristics, including low temperature, less dissolved $\mathrm{O}_{2}$, and co-existing ions, which could certainly influence As removal efficiency (Davis and Edwards, 2014; Meng et al., 2001), and which were not clearly investigated.

Molecular level information on groundwater As coagulation can provide great help in understanding the As removal mechanism and its subsequent remobilization from the produced residue. As co-precipitation with Fe salts in synthetic water has been investigated using microscopic techniques, including extended X-ray absorption fine structure (EXAFS), $\mathrm{X}$-ray absorption near-edge structure (XANES), and X-ray powder diffraction (XRD) (Chen et al., 2009; Jia et al., 2006). The results showed that precipitation of $\mathrm{As}(\mathrm{V})$ and $\mathrm{Fe}(\mathrm{III})$ or $\mathrm{As}$ surface complexation on the Fe hydroxide could occur and most probably be affected by $\mathrm{pH}$ and Fe/As molar ratios. However, limited microscopic investigation has been carried out comparing the As treatment mechanisms using mono- and poly-Fe salts, especially in real groundwater matrices.

The objective of this study was to comparatively evaluate the on-site groundwater As removal performance and mechanism using ferric sulfate (FS) and polyferric sulfate (PFS) from macro- to microscopic levels. Multiple-scale explorations were conducted by complementary techniques, including macroscopic coagulation experiments, dynamic floc size measurements, leaching tests, and molecular techniques including Fe k-edge XANES and As k-edge EXAFS analysis. This study should improve the fundamental understanding of groundwater As coagulation and filtration processes by mono- and poly-coagulants, and finally provide a practical solution for water treatment in As-geogenic areas.

\section{Materials and methods}

\subsection{Materials and methods}

Stock solutions were prepared with reagent grade $\mathrm{Na}_{3} \mathrm{AsO}_{4} \cdot 12$ $\mathrm{H}_{2} \mathrm{O}, \mathrm{Na}_{2} \mathrm{SO}_{4}, \mathrm{Ca}(\mathrm{ClO})_{2}, \mathrm{NaOH}$, and $\mathrm{HCl}$ (Sinopharm Chemical
Reagent Co. Ltd., Beijing, China). FS (industrial grade, 21\% as Fe) and PFS (industrial grade, $22 \%$ as Fe) were obtained from Bodi Chemical Co. Ltd. Tianjin, China. Ten groundwater samples (G1G10 in Table 1) were randomly collected from Shanxi, China, where As contamination in groundwater prevails (Cui et al., 2013; Luo et al., 2012), and were used to evaluate water chemistry influences on As removal. Because the average As concentration in local groundwater was about $300 \mu \mathrm{g} / \mathrm{L}$ as reported in our previous study (Luo et al., 2012), three samples containing comparable or higher As levels including $321 \mu \mathrm{g} / \mathrm{L}$ (G5), $578 \mu \mathrm{g} / \mathrm{L}$ (G8), and $1067 \mu \mathrm{g} / \mathrm{L}$ (G10) were selected for further study. Finally, one groundwater sample (G5) was chosen for a filtration study using a two-bucket system in the field and subsequent exploration of the As removal mechanism.

\subsection{Procedures of As oxidation, coagulation, and filtration}

\subsubsection{Optimization of $\mathrm{Ca}(\mathrm{ClO})_{2}$}

$\mathrm{Ca}(\mathrm{ClO})_{2}$ was employed to oxidize the predominant As(III) in groundwater, as As(III) is less easily removed than $\mathrm{As}(\mathrm{V})$ (Mercer and Tobiason, 2008). The appropriate dose of $\mathrm{Ca}(\mathrm{ClO})_{2}$ was optimized by adding different doses into three groundwater samples (G5, G8, and G10) in the field. Samples were collected and filtered through a $0.22 \mu \mathrm{m}$ membrane filter after $30 \mathrm{~min}$, which is usually adequate for As(III) oxidation by $\mathrm{Ca}(\mathrm{ClO})_{2}$ (Sorlini and Gialdini, 2010). Furthermore, the kinetics of As(III) oxidation was recorded for the optimized dose of $\mathrm{Ca}(\mathrm{ClO})_{2}$. The As speciation in the oxidation samples was determined after collection on site.

\subsubsection{Optimization of $\mathrm{Fe}$ salt coagulation for As removal in batch experiment}

The appropriate dose of FS and PFS for As removal was optimized by adding different doses of Fe salts in three pre-oxidized groundwater samples (G5, G8, and G10) by $\mathrm{Ca}(\mathrm{ClO})_{2}$ in $100 \mathrm{~mL}$ plastic bottles on site. After the suspension was mixed for $30 \mathrm{~min}$ on a rotator, the final values of $\mathrm{pH}$ and residual chlorine were recorded and the samples were filtered through a $0.22-\mu \mathrm{m}$ membrane filter. The filtered water samples were acidified with $\mathrm{HCl}$ and then analyzed for total arsenic on site, and cation and anion analysis in the laboratory. The final optimized dose of FS and PFS with $\mathrm{Ca}(\mathrm{ClO})_{2}$ was mixed and sealed in a vacuumed plastic packet for the following bucket performance tests.

To study the kinetics of As removal, batch experiments were performed by mixing groundwater with the sealed chemicals of FS or PFS with $\mathrm{Ca}(\mathrm{ClO})_{2}$ in a $20 \mathrm{~L}$ bucket. Samples were taken at designed time intervals and passed through a $0.22-\mu \mathrm{m}$ membrane filter for soluble As analysis.

\subsubsection{As coagulation and filtration in two-bucket systems} To investigate the effect of the initial As concentration and groundwater chemistry, $18 \mathrm{~L}$ of ten groundwater samples were loaded in a 20-L bucket, and mixed with the sealed chemicals containing the optimized dose of $2.4 \mathrm{~g}$ FS or $2.0 \mathrm{~g}$ PFS with $0.1 \mathrm{~g} \mathrm{Ca}(\mathrm{ClO})_{2}$ (Fig. 1a).

To conveniently supply As-safe drinking water for local residents, a two-bucket system was designed as shown in Fig. 1b, which integrated the coagulation and filtration processes together. Generally, 18 L newly pumped groundwater was 
Table 1 - Water parameters of ten groundwater samples (G1-G10) (mg/L).

\begin{tabular}{|c|c|c|c|c|c|c|c|c|c|c|}
\hline Parameters & G1 & G2 & G3 & G4 & $\mathrm{G}^{\mathrm{b}}$ & G6 & G7 & $G 8^{b}$ & G9 & G10 b \\
\hline $\mathrm{pH}$ & 8.6 & 8.4 & 8.1 & 7.5 & 8.7 & 8.3 & 7.6 & 8.2 & 8.4 & 8.5 \\
\hline $\mathrm{ORP}(\mathrm{mV})$ & -107.0 & -6.0 & -66.0 & -90.0 & -138.0 & -154.0 & -66.0 & -131.0 & -83.0 & -148.0 \\
\hline Cond $(\mathrm{mS} / \mathrm{cm})$ & 0.4 & 0.5 & 0.5 & 5.3 & 0.5 & 0.5 & 0.5 & 0.6 & 0.5 & 0.5 \\
\hline Turbidity (NTU) & 8.5 & 1.6 & 17.9 & 2.9 & 4.2 & 0.8 & 17.9 & 3.4 & 14.6 & 37.3 \\
\hline $\mathrm{DO}(\mathrm{mg} / \mathrm{L})$ & 0.0 & 1.0 & 0.0 & 0.0 & 0.0 & 0.0 & 0.0 & 0.0 & 0.0 & 0.0 \\
\hline TDS (g/L) & 0.3 & 0.3 & 0.3 & 3.4 & 0.3 & 0.3 & 0.3 & 0.4 & 0.3 & 0.3 \\
\hline Temperature $\left({ }^{\circ} \mathrm{C}\right)$ & 10.6 & 11.2 & 11.8 & 10.8 & 10.5 & 10.1 & 11.1 & 9.9 & 10.4 & 11.7 \\
\hline As & 0.136 & 0.117 & 0.207 & 0.224 & 0.321 & 0.384 & 0.430 & 0.578 & 0.969 & 1.067 \\
\hline As(III) (\%) & 96 & 78 & 85 & 77 & 95 & 87 & 98 & 89 & 63 & 86 \\
\hline $\mathrm{F}$ & 0.26 & 0.13 & 0.17 & 0.12 & 0.16 & 0.40 & 0.14 & 0.12 & 0.31 & 0.32 \\
\hline $\mathrm{Cl}$ & 221.7 & 24.88 & 418.5 & 5.11 & 12.89 & 14.36 & 20.82 & 37.30 & 12.01 & 10.89 \\
\hline $\mathrm{Br}$ & 28.51 & 3.78 & 18.28 & 2.13 & 1.62 & 3.51 & 21.26 & 10.71 & 16.23 & 4.08 \\
\hline $\mathrm{PO}_{4}$ & 0.14 & 0.10 & 0.14 & 0.11 & 0.11 & $<0.02$ & 0.13 & 0.09 & 0.11 & $<0.02$ \\
\hline $\mathrm{NO}_{3}$ & $<0.01$ & 0.81 & $<0.01$ & 0.47 & 0.32 & 0.32 & 0.60 & 0.54 & $<0.01$ & $<0.01$ \\
\hline $\mathrm{NO}_{2}$ & 17.93 & 7.23 & 12.30 & 9.70 & 11.27 & 11.46 & 9.88 & 7.31 & 12.18 & 12.47 \\
\hline $\mathrm{SO}_{4}$ & 164.6 & 35.04 & 267.2 & 3.60 & 0.33 & 0.58 & 8.09 & 21.63 & 0.24 & 0.14 \\
\hline $\mathrm{Na}$ & 54.6 & 16.0 & 62.3 & 11.5 & 13.7 & 10.0 & 11.5 & 17.8 & 14.9 & 11.8 \\
\hline $\mathrm{K}$ & 1.0 & 0.9 & 33.8 & 0.1 & 1.5 & 0.3 & 2.4 & 3.1 & 4.8 & 1.3 \\
\hline $\mathrm{Mg}$ & 94.6 & 15.8 & 91.5 & 13.5 & 21.1 & 9.6 & 14.4 & 24.7 & 22.0 & 19.6 \\
\hline $\mathrm{Ca}$ & 123.4 & 37.1 & 85.6 & 5.5 & 25.7 & 25.8 & 17.6 & 35.4 & 19.0 & 15.7 \\
\hline $\mathrm{Si}$ & 4.90 & 4.60 & 3.06 & 3.63 & 4.92 & 4.60 & 3.93 & 5.33 & 3.31 & 2.72 \\
\hline Ionic strength $(\mathrm{mol} / \mathrm{L})^{c}$ & 0.022 & 0.005 & 0.025 & 0.002 & 0.004 & 0.003 & 0.003 & 0.005 & 0.004 & 0.003 \\
\hline \multicolumn{11}{|c|}{$\begin{array}{l}\text { a Detection limit (DL) of } \mathrm{PO}_{4} \text { was } 0.02 \mathrm{mg} / \mathrm{L} \text {, DL of Fe was } 0.01 \mathrm{mg} / \mathrm{L} \text {, and DL of Al was } 0.1 \mathrm{mg} / \mathrm{L} \text {. These three components in the ten groundwater } \\
\text { samples were all below the detection limit. } \\
\text { b Representative groundwater samples of G5, G8 and G10 with different As concentrations were chosen for further treatment, respectively, and } \\
\text { G5 was selected for bucket system study. } \\
\text { c The ionic strength was calculated using the following equation: } I=\frac{1}{2} \sum_{i=1}^{n} c_{i} z_{i}^{2} \text {, where } c_{i}(\mathrm{~mol} / \mathrm{L}) \text { is the molar concentration of ion } \mathrm{I}, z_{\mathrm{i}} \text { is the charge } \\
\text { number, and the sum is taken over all ions determined in the groundwater. }\end{array}$} \\
\hline
\end{tabular}

loaded in one single bucket, and a packet of the mixed chemicals was added, mixed for $10 \mathrm{~min}$, and settled for another $20 \mathrm{~min}$. The final suspension containing the freshly formed Fe hydroxide flocs was gently poured into the up-bucket (diameter of $32 \mathrm{~cm}$ and height of $30 \mathrm{~cm}$ ), and penetrated through the sand layer ( $8 \mathrm{~cm}$ thick), which retained the Fe flocs. The residual chlorine was removed by the following activated carbon (AC)

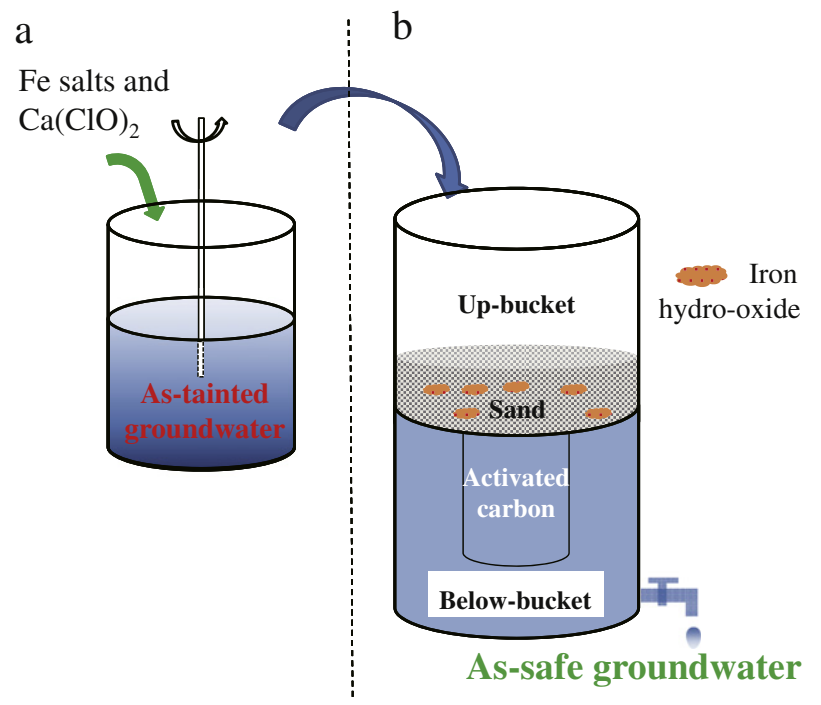

Fig. 1 - Scheme of As coagulation (a) in one bucket experiment and filtration (b) with two-bucket system. column (diameter of $6 \mathrm{~cm}$ and height of $17 \mathrm{~cm}$ ). As-safe water was collected from a tube connected to the bottom of the below-bucket (diameter of $32 \mathrm{~cm}$ and height of $40 \mathrm{~cm}$ ). With increasing quantities of filtered water, Fe flocs would clog the sand layer and resulted in an unacceptable filtration time for a bucket (>90 min per bucket, from interviewing the local residents), which was considered as a filtration cycle. The sand layer was then washed to remove the retained Fe flocs and reused for the next filtration cycle. The final residual sludge after sand washing was collected and taken to the laboratory, washed with DI water to $<100 \mu \mathrm{S} / \mathrm{cm}$ to remove any soluble components, and freeze-dried for further analysis.

\subsection{Dynamic floc size of FS and PFS coagulation in groundwater}

The coagulation was performed using a jar test apparatus (JTY-6, Daiyuan Jar Test Instruments, Beijing, China) using the optimized dose of FS and PFS. The dynamic floc size during coagulation was measured by a laser diffraction instrument (Mastersizer 2000, Malvern, UK) using a peristaltic pump (BT00-300M, Longer Pump, Baoding, China) according to a previous study (Lin et al., 2008). 1 L of G5 was transferred into a $1 \mathrm{~L}$ square beaker and agitated at $250 \mathrm{r} / \mathrm{min}$ for $0.5 \mathrm{~min}$. Subsequently, the coagulant stock solution was added followed by agitating at $200 \mathrm{r} / \mathrm{min}$ for $1.5 \mathrm{~min}$ and $40 \mathrm{r} / \mathrm{min}$ for $10 \mathrm{~min}$. To study the floc breakage and re-growth characteristics, the aggregated flocs were re-exposed to the shear force at $200 \mathrm{r} / \mathrm{min}$ for $2 \mathrm{~min}$ followed by $40 \mathrm{r} / \mathrm{min}$ for $20 \mathrm{~min}$. The 
floc growth rate, strength factor $\left(S_{f}\right)$, recovery factor $\left(R_{f}\right)$, and fractal dimension $\left(D_{\mathrm{f}}\right)$ calculation methods are detailed in Appendix A Supplementary data.

\subsection{EXAFS analysis}

To explore the As removal mechanism by Fe coagulation, Fe $\mathrm{k}$-edge XANES and As k-edge EXAFS spectra for the two field solid residue samples were collected. For comparison, FS and PFS of the same dose were added into $0.1 \mathrm{~mol} / \mathrm{L} \mathrm{Na}_{2} \mathrm{SO}_{4}$ solution, stirred for $4 \mathrm{hr}$ with $500 \mu \mathrm{g} / \mathrm{L} \mathrm{As}(\mathrm{V})$ or without. The $\mathrm{pH}$ was adjusted to 7.5 with $5 \mathrm{~mol} / \mathrm{L} \mathrm{NaOH}$ according to the field experiment. The four simulated suspension samples were collected, washed with DI water to $<100 \mu \mathrm{S} / \mathrm{cm}$ to remove any soluble components, centrifuged at $8000 \mathrm{r} / \mathrm{min}$ for $10 \mathrm{~min}$, and vacuum freeze-dried for further analysis.

The samples were sealed between two layers of Kapton tape, and analyzed on beamline 14W1 at the Shanghai Synchrotron Radiation Facility, China. Fe k-edge (7112 eV) XANES spectra were acquired with an energy range of -200 to $400 \mathrm{eV}$ in transmission mode. A series of ten Fe-bearing reference compounds was measured. The selection of $\mathrm{Fe}$ references for linear combination fit (LCF) analysis was tested by principal component analysis and target transformation testing in the SIX-PACK code (Malinowski, 1978; Webb, 2005). As k-edge (11,867 eV) EXAFS spectra were collected with an energy range of -200 to $1000 \mathrm{eV}$ in fluorescence mode. The Fe k-edge XANES and As k-edge EXAFS spectra were analyzed using methods described in our previous reports (Du et al., 2014; Jing et al., 2012; Luo et al., 2010) and detailed in Appendix A Supplementary data.

\subsection{Safety evaluation for coagulated solid residue}

To evaluate whether the coagulated solid residue could be safely disposed as landfill, the leaching potential of As was evaluated using three methods including the toxicity characteristic leaching procedure (TCLP) (US EPA, 1992), synthetic precipitation leaching procedure (SPLP) (Clancy et al., 2013), and California waste extraction test (WET) (Clancy et al., 2013) with details in Appendix A Table S1. Triplicate samples were placed in a capped polypropylene bottle in a rotator at $30 \mathrm{r} / \mathrm{min}$ for the required time, and filtered through a $0.22-\mu \mathrm{m}$ membrane filter for As analysis.

\subsection{Analysis}

The As speciation was determined using high-performance liquid chromatography (HPLC) coupled with a hydride generation atomic fluorescence spectrometer (HG-AFS-8130, Jitian, Beijing, China) installed in a local farmer's house (Cui et al., 2013). Briefly, online separation of As species was carried out with a Hamilton PRP-X100 anion exchange column, using $15 \mathrm{mmol} / \mathrm{L}$ phosphate buffer at $\mathrm{pH} 6$ as mobile phase at $1.0 \mathrm{~mL} / \mathrm{min}$ flow rate. The detection limit was $1.7 \mu \mathrm{g} / \mathrm{L}$ for $\mathrm{As}(\mathrm{V})$ and $0.7 \mu \mathrm{g} / \mathrm{L}$ for $\mathrm{As}(\mathrm{III})$. The total As concentration was measured using HG-AFS with a detection limit of $0.6 \mu \mathrm{g} / \mathrm{L}$ and detailed in Appendix A Supplementary data. Anions including $\mathrm{Cl}^{-}, \mathrm{NO}_{3}^{-}, \mathrm{NO}_{2}^{-}, \mathrm{SO}_{4}^{2-}$, and $\mathrm{PO}_{4}^{3-}$ were measured using an ion chromatography system (DX-1100, Dionex., Sunnyvale, USA).
Concentrations of dissolved cations including $\mathrm{Fe}, \mathrm{Si}, \mathrm{Ca}, \mathrm{Mg}$, $\mathrm{Na}^{+}$, and $\mathrm{K}^{+}$were determined using an inductively coupled plasma optical emission spectrometer (ICP-OES, Optima 8300, PerkinElmer, Akron, USA). The residual chlorine was determined on site using two drops of orthotolidine reagent solution in $10 \mathrm{~mL}$ filtered water by comparing the color against a color chart with a range of 0.2 to $10 \mathrm{mg} / \mathrm{L}$. The turbidity of the treated water after the two-bucket systems was directly measured using a $2100 \mathrm{Q}$ portable turbidimeter (Hach, Colorado, USA).

\section{Results and discussion}

\subsection{Optimization of $\mathrm{Ca}(\mathrm{ClO})_{2}$ oxidant}

Higher doses of $\mathrm{Ca}(\mathrm{ClO})_{2}$ resulted in more oxidation of $\mathrm{As}(\mathrm{III})$, and $>5 \mathrm{mg} / \mathrm{L} \mathrm{Ca}(\mathrm{ClO})_{2}$ was sufficient to oxidize 305-1067 $\mu \mathrm{g} / \mathrm{L}$ As(III) in three groundwater samples (Fig. 2a). The optimized dose of $5 \mathrm{mg} / \mathrm{L} \mathrm{Ca}(\mathrm{ClO})_{2}$ is much higher than the theoretical requirement for $\mathrm{Ca}(\mathrm{ClO})_{2}(0.6-1.8 \mathrm{mg} / \mathrm{L})$ according to Eq. (8) (Appendix A Table S2). The extra $\mathrm{Ca}(\mathrm{ClO})_{2}$ may be consumed by the co-existing oxidant-scavenging constituents, including $\mathrm{S}^{2-}$, $\mathrm{NO}_{2}^{-}$, and dissolved organic matter (Dodd et al., 2006), highlighting the effects of groundwater matrices on As(III) oxidation efficiency.

With the dose of $5 \mathrm{mg} / \mathrm{L} \mathrm{Ca}(\mathrm{ClO})_{2}, 90 \%$ of $\mathrm{As}$ (III) was oxidized after $5 \mathrm{~min}$ and no As(III) was observed after $20 \mathrm{~min}$ (Fig. 2b). The oxidation time of $20 \mathrm{~min}$ is sufficient for the As treatment process in the two-bucket system. A previous study using $3.0 \mathrm{mg} / \mathrm{L} \mathrm{NaClO}$ (Sorlini and Gialdini, 2010) demonstrated that $1 \mathrm{~min}$ was adequate for $100 \%$ oxidation of $14.6 \mu \mathrm{g} / \mathrm{L}$ groundwater As(III), whereas, the longer time of 5 min was needed for $95 \%$ oxidation of $50 \mu \mathrm{g} / \mathrm{L}$ As(III). Thus, a higher concentration of As(III) should contribute to the slower oxidation of $\mathrm{As}(\mathrm{III})$ to $\mathrm{As}(\mathrm{V})$.

\subsection{Dosage optimization of FS and PFS in three groundwater samples}

Higher doses of Fe salt resulted in better As removal from G5, G8, and G10 (Fig. 3a-c). As removal kinetics showed that no As was observed after less than $5 \mathrm{~min}$ for both FS and PFS (Appendix A Fig. S1). Nevertheless, PFS exhibited a slightly better As removal efficiency than FS (Fig. 3a-c). The higher As removal efficiency of PFS than FS with the same dose is attributable to the presence of optimized multinuclear hydroxyl complexes, which could minimize the hydrolysis reactions so that it is more effective for As removal (Cheng, 2002; Liang et al., 2009). Furthermore, the temperature range for the newly pumped groundwater was $9.9-11.8^{\circ} \mathrm{C}$ (Table 1), which could pose less of a problem for As removal by PFS compared with FS (Fan et al., 2003), suggesting that PFS is more appropriate than FS in actual groundwater treatment. To ensure that the As level in treated water is less than $10 \mu \mathrm{g} / \mathrm{L}$, we selected $0.12 \mathrm{~g} \mathrm{FS} / \mathrm{L}$ (25.2 mg Fe/L) and $0.10 \mathrm{~g}$ PFS/L (25.2 mg $\mathrm{Fe} / \mathrm{L})$ for further study.

During As coagulation, many studies have reported that coexisting ions, including the analogous $\mathrm{Si}$ and $\mathrm{P}$, could inhibit As removal (Meng et al., 2000). As in our study, no P was 


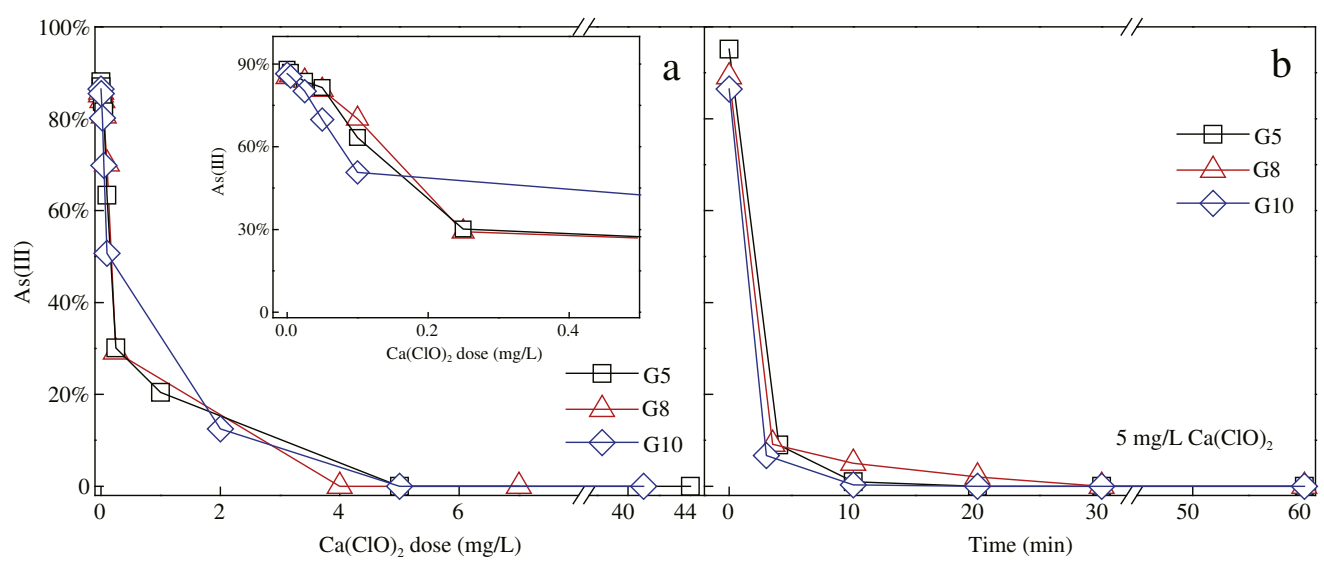

Fig. 2 - As(III) percentage after reacting with increasing amounts of $\mathrm{Ca}(\mathrm{ClO})_{2}$ at $30 \mathrm{~min}$ (a), and $\mathrm{As}$ (III) percentage as a function of time with $5 \mathrm{mg} / \mathrm{L} \mathrm{Ca}(\mathrm{ClO})_{2}$ (b) in three groundwater samples G5 (321 $\mu \mathrm{g} / \mathrm{L}$ of total As with 95\% in As(III)), G8 (578 $\mu$ g/L of total As with $89 \%$ in As(III)), and G10 (1067 $\mu \mathrm{g} / \mathrm{L}$ of total As with $86 \%$ in As(III)).

observed, and $\mathrm{Si}$ is prevalent in the groundwater samples (Table 1). The results showed that $\mathrm{Si}$ was reduced with increasing doses of Fe salt (Fig. 3d-f). The groundwater $\mathrm{pH}$ decreased with increasing Fe dose (Fig. 3g-i), which was caused by the protons released from the coagulation reaction (Appendix A Table S2). Nevertheless, the $\mathrm{pH}$ range of 7.12 to 7.48 at the optimized dose of Fe salts is favorable for As removal by ferric coagulation, and the $\mathrm{pH}$ adjustment procedure can be omitted.

\subsection{Comparison of FS and PFS in ten groundwater samples}

To see the effect of water chemistry and various initial As concentrations on As removal, coagulation in one bucket was
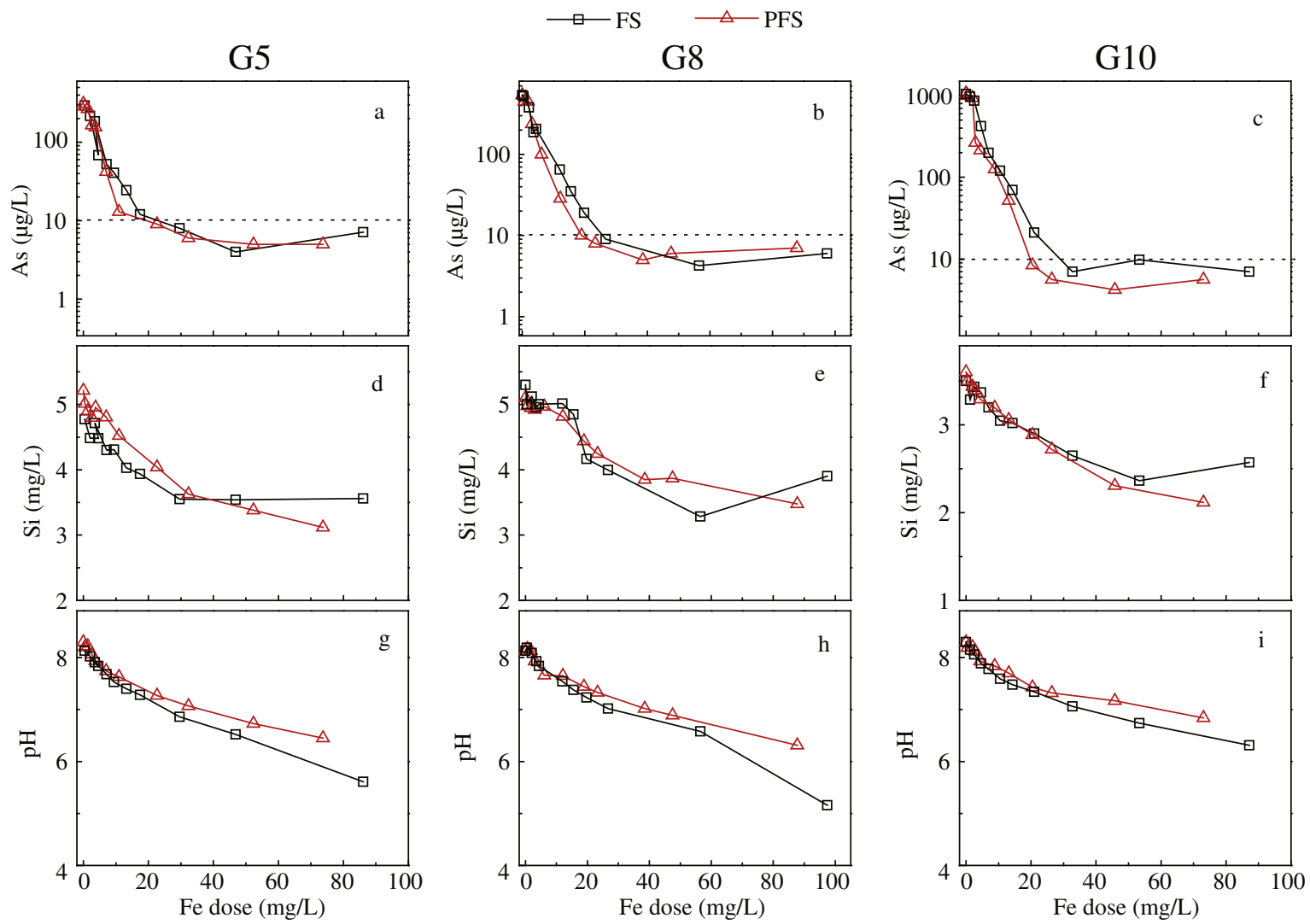

Fig. 3 - Change of As, Si, and pH after different doses of ferric sulfate and polyferric sulfate in groundwater samples G5, G8, and G10. The horizontal dashed lines in panels a-c represent the recommended As level $(10 \mu \mathrm{g} / \mathrm{L})$ in drinking water. 
performed using FS and PFS in ten groundwater samples. The results indicated that all the filtered As concentrations were below $10 \mu \mathrm{g} / \mathrm{L}$ using FS, whereas three of ten effluent samples using PFS exhibited a slightly higher As concentration than $10 \mu \mathrm{g} / \mathrm{L}$ As, i.e., ranging from 10.8 to $14.7 \mu \mathrm{g} / \mathrm{L}$ (Fig. 4a).

The As removal efficiency in the coagulation process could be affected by many factors including Fe/As molar ratios, coexisting ions, and water chemistry (Meng et al., 2000, 2001; Mercer and Tobiason, 2008). The results showed that $>95 \%$ of 13.6-1067 $\mu \mathrm{g} / \mathrm{L}$ As in the ten groundwater samples was removed by the initial Fe/As molar ratios from 28 to 2489 . This result is in line with a previous report that $>95 \%$ of $500 \mu \mathrm{g} / \mathrm{L}$ As could be removed at Fe/As molar ratios greater than 20 in saline solutions (Mercer and Tobiason, 2008). In another study using the Bangladesh groundwater, $98.6 \%$ of the filtered samples showed less than $50 \mu \mathrm{g} / \mathrm{L}$ As with Fe/As molar ratios from 47 to 188 (Cheng et al., 2004). Thus, Fe dose played a key role in As removal efficiency from groundwater, which was further demonstrated by a significant negative correlation between the residual As concentrations and Fe/As molar ratios in this study $(r=-0.721, p<0.05$ for both coagulants in Appendix A Table S3, $n=10$ ). The three effluent samples with $>10 \mu \mathrm{g} / \mathrm{L}$ using PFS should not be caused by Fe dose, as that the same Fe dose could remove higher As concentrations such as that in G10. The discrepancy is likely to be attributable to the composite effects of the complex groundwater matrices.

Besides the effect of Fe/As molar ratios, the coagulation results demonstrated that $\mathrm{Si}$ can also be removed by FS and PFS (Fig. 4b) and could affect As removal. Si could occupy the surface sites, and subsequently have a negative effect on As removal (Maiti et al., 2012; Meng et al., 2000). This was also evidenced by the significant negative correlation between As removal efficiency and influent $\mathrm{Si}$ concentration $(r=-0.721$, $p<0.05, \mathrm{n}=10, \mathrm{FS}$ in Appendix A Table S3).

The increasing levels of $\mathrm{SO}_{4}^{2-}$ (Fig. 4c) in effluent samples were attributed to Fe salt addition. Effluent $\mathrm{NO}_{3}^{-}$concentrations slightly increased with decreasing concentrations of $\mathrm{NO}_{2}^{-}$ (Fig. $4 \mathrm{~d}-\mathrm{e}$ ) due to oxidation of $\mathrm{NO}_{2}^{-}$to $\mathrm{NO}_{3}^{-}$by $\mathrm{Ca}(\mathrm{ClO})_{2}$. Other common ions including $\mathrm{Cl}^{-}, \mathrm{Na}, \mathrm{Ca}$, and $\mathrm{Mg}$ were generally not changed after coagulation (Fig. $4 \mathrm{f}-\mathrm{i}$ ). The existence of $\mathrm{Ca}$ and $\mathrm{Mg}$ could reduce the adverse effects of anions on As removal (Meng et al., 2000). No dissolved Fe (<0.01 mg/L) was detected in the ten treated water samples.

\subsection{Comparison of FS and PFS in bucket systems}

The treated water exhibited continuous As levels $<10 \mu \mathrm{g} / \mathrm{L}$ using FS and PFS in the two-bucket system (Fig. 5a). As levels possibly higher than $10 \mu \mathrm{g} / \mathrm{L}$ after one-bucket coagulation
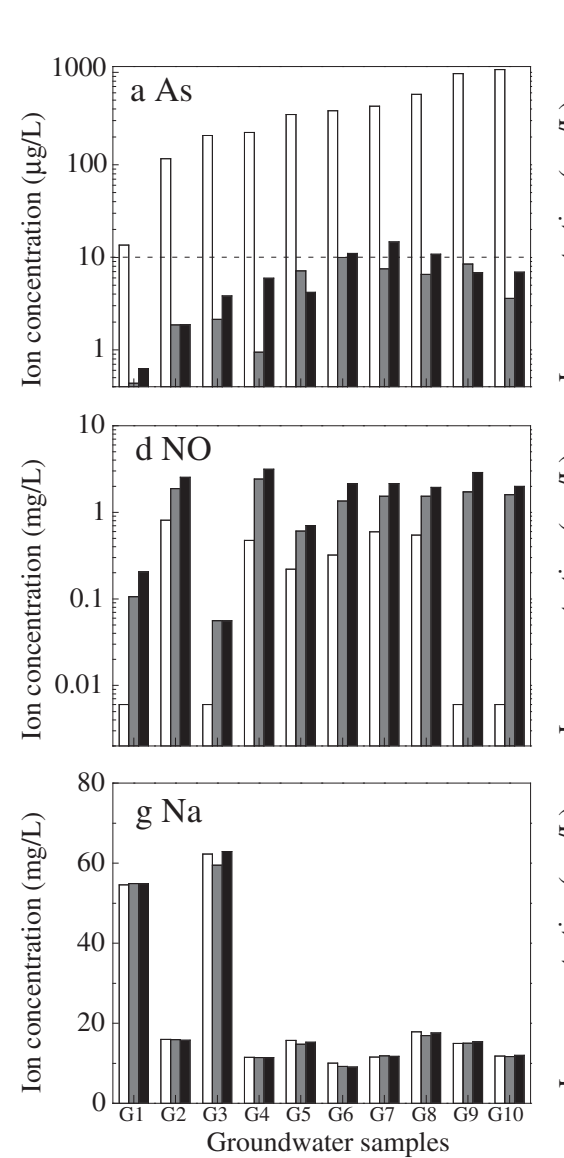
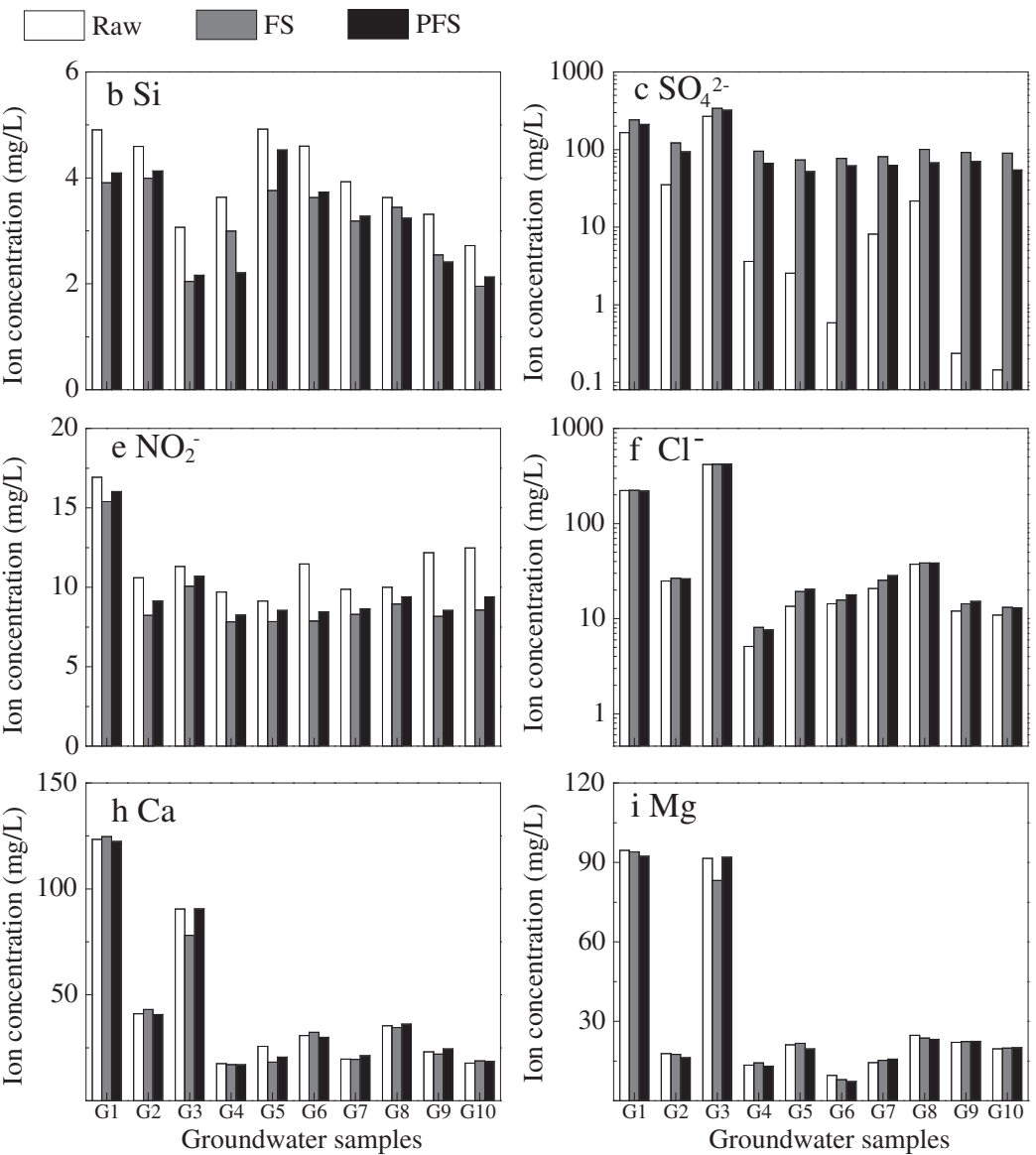

Fig. 4 - Change of As and coexisting ions in ten groundwater samples (G1-G10, Appendix A Table S1) before and after 2.4 g ferric sulfate (FS) and $2.0 \mathrm{~g}$ polyferric sulfate (PFS) addition in $18 \mathrm{~L}$ groundwater in one-bucket experiments. The horizontal dashed line in panel a represents the recommended As level $(10 \mu \mathrm{g} / \mathrm{L})$ in drinking water. 
(Fig. 4a) could be removed by the subsequent freshly formed Fe oxide layer retained on the top of the sand layer, assuring the safety of the treated water. The system was efficiently conducted for five cycles, i.e., 27 buckets for FS and 30 buckets for PFS (Fig. 5b), respectively. The filtration time for each bucket is crucial for continuous water demand. During the five cycles, each bucket of $18 \mathrm{~L}$ water needed a filtration time varying from $8 \mathrm{~min}$ to $86 \mathrm{~min}$. Thus using the two-bucket system, $18 \mathrm{~L}$ As-safe groundwater could be supplied for local residents within $90 \mathrm{~min}$.

Similar to the one bucket experimental results, Si was also removed by FS and PFS (Fig. 5c). The effluent levels of $\mathrm{Na}, \mathrm{Ca}$, $\mathrm{Mg}, \mathrm{Cl}^{-}$, and other coexisting ions showed no significant change after filtration of the raw groundwater (Appendix A Figs. S2-3). Fe was not observed in the filtrate samples during the five cycles and, hence, the potential synergistic toxicity of soluble As and Fe could be avoided (Mohan Chandrasekaran et al., 2010). The residual chlorine concentration was less than $1 \mathrm{mg} / \mathrm{L}$ after filtration (Appendix A Figs. S2-3), as the sand layer and activated carbon column could adsorb some residual chlorine and reduce its quantity in the treated water. The effluent $\mathrm{pH}$ was 7.0-8.2 (Fig. 5d), which was about 1-0.2 unit lower than the initial groundwater due to Fe salt coagulation. The turbidity in the effluent ranged from 0.3 to 4.5 NTU (Appendix A Figs. S2-3), which satisfied the rural drinking water standard in China (5 NTU, GB 5749-2006).

The filtration time was lengthened by the increasing quantity of retained Fe flocs, which blocked the sand layer. The retained co-existing ions could affect the Fe flocs' behavior. In addition, the physico-chemical properties of these Fe flocs can directly affect the performance of the two-bucket system using FS and PFS, and were further studied.

\subsection{Floc properties of FS and PFS coagulation in G5}

To compare the floc properties of FS and PFS, dynamic floc size was determined in sample G5 using a jar test apparatus (Fig. 6). The floc growth rate calculation (Appendix A Supplementary data) indicated that PFS showed a lower rate
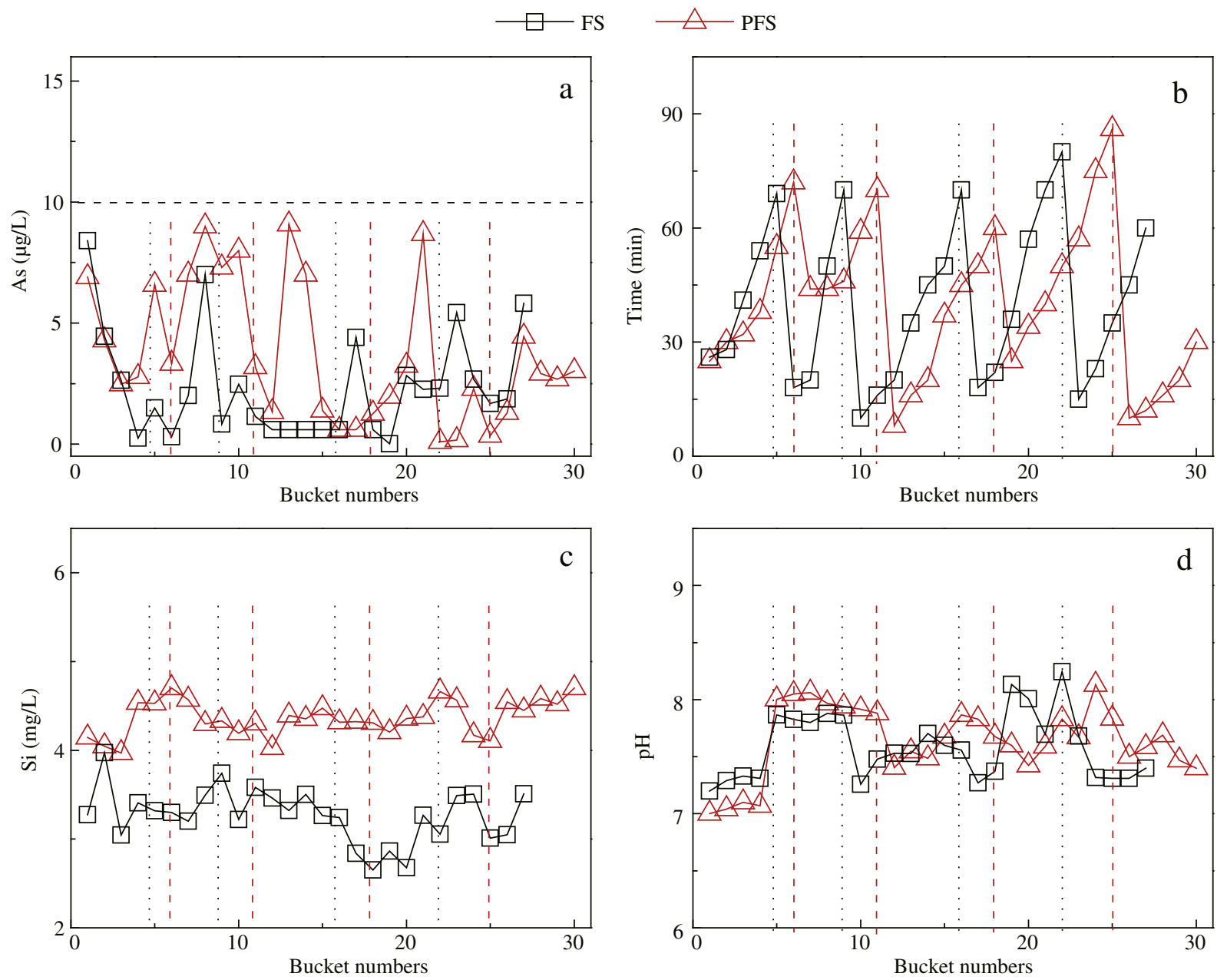

Fig. 5 - Effluent concentrations of As (a), filtration time (b), Si (c), and pH (d) after ferric sulfate (FS) and polyferric sulfate (PFS) treatment for G5 using two-bucket system. The horizontal dashed line in panel a represents the recommended As level (10 $\mu \mathrm{g} /$ L) in drinking water. The vertical dashed lines indicated one cycle in which the sand layer and the activated carbon column were washed to remove any Fe flocs from FS (black) and PFS (red) during filtration. 

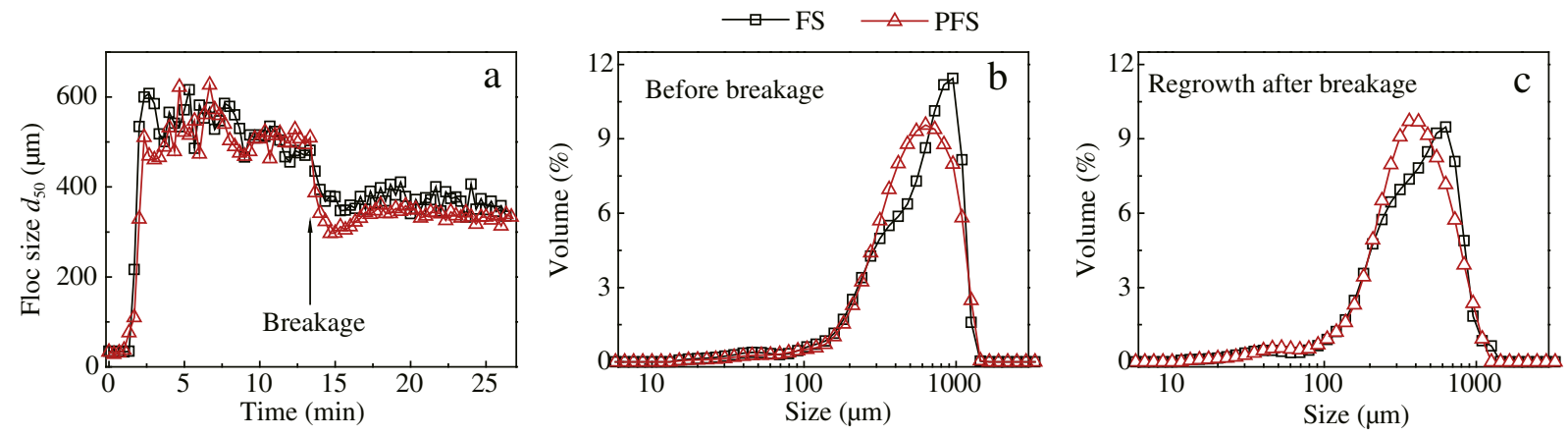

Fig. 6 - Floc formation, breakage, and re-growth dynamics (a), floc size distribution before breakage (b), and re-growth after breakage (c) with $0.12 \mathrm{~g} / \mathrm{L}$ ferric sulfate (FS) or $0.10 \mathrm{~g} / \mathrm{L}$ polyferric sulfate (PFS) in G5.

(502.4 $\mu \mathrm{m} / \mathrm{min})$ than FS $(565.3 \mu \mathrm{m} / \mathrm{min})$. This is because the pre-optimized multinuclear hydroxyl complexes in PFS are slower to hydrolyze than monomeric FS (Cheng, 2002).

During coagulation, FS showed a similar floc size distribution to that of PFS before or after breakage (Fig. 6b-c). During regrowth after breakage, flocs from both FS and PFS did not recover to the initial floc sizes, probably because of the poor re-growth ability of sweep flocs due to physical forces (Zhao et al., 2011). Floc breakage and recoverability calculations (Appendix A Supplementary data) indicated that the recovery factor of FS (5.9\%) was much lower than PFS (16.8\%), suggesting that FS exhibited much weaker recoverability than PFS (Zhao et al., 2011). A higher $D_{\mathrm{f}}$ value (2.65) was obtained for PFS than FS (2.58) during coagulation (Appendix A Table S4), indicating that PFS generated more densely packed aggregates. Hence the flocs formed by PFS could settle down more easily, which is beneficial for groundwater treatment.

\subsection{Fe k-edge XANES characterization of the coagulated solid residue}

In addition to studying the effluent water chemistry and coagulation process, the coagulated solid residue was characterized using XANES analysis to investigate the coagulation mechanism. Although six components were found using principal component analysis for the coagulated solid residue (Appendix A Table S5), the ten Fe references showed SPOIL values $<6$ based on target transformation testing (Appendix A Table S6) and were employed in LCF analyses. The LCF results demonstrated a good fit between the XANES spectra and linear combinations of the reference spectra (Fig. 7). Ferrihydrite (Fh) contributed to $90 \%$ and $87 \%$ for FS- and PFS-coagulated residue using groundwater, respectively (Table 2). A contribution of $94 \%$ to $100 \%$ of $\mathrm{Fh}$ was calculated for the simulated samples using $0.1 \mathrm{~mol} / \mathrm{L} \mathrm{Na}_{2} \mathrm{SO}_{4}$ either with As or without. Fh dominated in the six solid residue samples because of the coagulation conditions with an Fe/As molar ratio of 92-105 at pH 7.0-8.6, as Fh tended to be generated with $\mathrm{As}(\mathrm{V})$ in $\mathrm{Fe}(\mathrm{III})$ solution Fe/As molar ratios $\geq 8$ at pH 8 (Jia et al., 2006). The freshly formed Fh favors As removal because it has an anomalous structure, larger specific area, and more highly reactive surfaces, and consequently exhibits higher As adsorption capacity than goethite and other Fe (hydr)oxides (Michel et al., 2007). Nevertheless, a slightly higher percentage of goethite was observed in groundwater matrices (7\%-8\%) than that in $0.1 \mathrm{~mol} / \mathrm{L} \mathrm{Na}_{2} \mathrm{SO}_{4}(0 \%-2 \%)$
(Table 2). This difference should reflect the influence of the co-removed components from groundwater on Fe flocs.

Scorodite $\left(\mathrm{FeAsO}_{4}\right)$ or poorly-crystalline ferric arsenate was not observed in the coagulated solid residue by LCF analysis. The former phase, scorodite, was usually generated over the

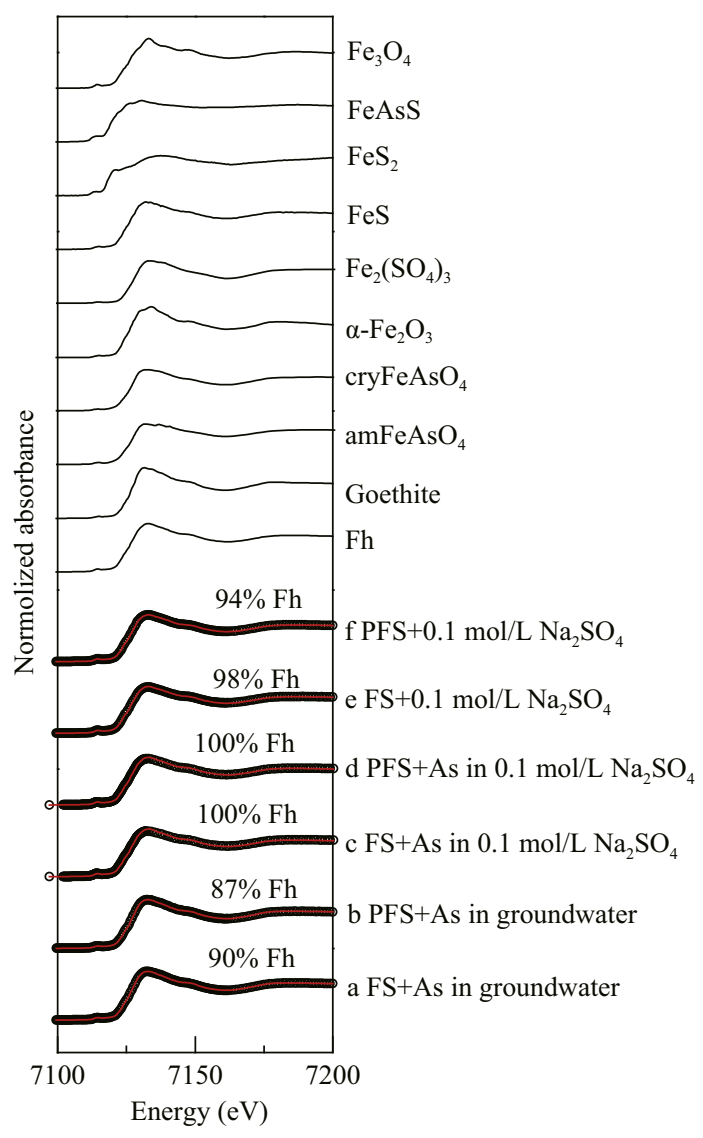

Fig. 7 - Fe k-edge X-ray absorption near-edge structure (XANES) spectra of coagulated solid residue in groundwater, with $500 \mu \mathrm{g} / \mathrm{L} \mathrm{As}(\mathrm{V})$ in $0.1 \mathrm{~mol} / \mathrm{L} \mathrm{Na}_{2} \mathrm{SO}_{4}$, and $0.1 \mathrm{~mol} / \mathrm{L} \mathrm{Na}_{2} \mathrm{SO}_{4}$ at pH 7.5 adjusted using $5 \mathrm{~mol} / \mathrm{L} \mathrm{NaOH}$. The inset percentages represent the ferrihydrite (Fh) proportion. Experimental and calculated curves are displayed as symbols and red lines, respectively. All fit parameters are detailed in Table 2 . 
Table 2 - SPOIL values of references obtained by target transformation, and linear combination fit (LCF) results of the six coagulated solid samples with a-f information in

\begin{tabular}{|c|c|c|c|c|c|c|c|c|}
\hline \multirow[t]{2}{*}{ References } & \multicolumn{2}{|c|}{$\begin{array}{l}\text { SPOIL values of } \\
\text { the references }\end{array}$} & \multicolumn{6}{|c|}{ LCF results (\%) } \\
\hline & Spoil & $R$ & $\mathrm{a}$ & $\mathrm{b}$ & C & $\mathrm{d}$ & e & $\mathrm{f}$ \\
\hline $\mathrm{Fh}$ & 2.5654 & $1.8 \mathrm{E}-05$ & 90 & 87 & 100 & 100 & 98 & 94 \\
\hline Gt & 2.1698 & $1.6 \mathrm{E}-04$ & 7 & 8 & 0 & 0 & 0 & 2 \\
\hline $\mathrm{Fe}_{2} \mathrm{O}_{3}$ & 1.8342 & $0.8 \mathrm{E}-03$ & 1 & 3 & 0 & 0 & 2 & 3 \\
\hline $\mathrm{Fe}_{2}\left(\mathrm{SO}_{4}\right)_{3}$ & 1.1512 & $1.6 \mathrm{E}-03$ & 2 & 2 & 0 & 0 & 0 & 1 \\
\hline R-factor & & & 0.0001 & 0.0001 & 0.0012 & 0.0006 & 0.0003 & 0.0003 \\
\hline Chi-square & & & 0.0056 & 0.0067 & 0.1087 & 0.0539 & 0.0120 & 0.0101 \\
\hline
\end{tabular}

$\mathrm{pH}$ range of 1-4.5 with a low Fe/As molar ratio of 1 (Chen et al., 2009), while the latter phase, poorly-crystalline ferric arsenate, generally formed at $\mathrm{pH} 3-5$ with Fe/As molar ratio of 2-8 (Jia et al., 2006). Thus these two phases possibly could not form in our experimental conditions.

Overall, no significant phase difference between FS and PFS residue was observed using Fe k-edge XANES analysis, though a slight variation existed in their dynamic floc aggregation processes. The observation is consistent with a previous study (Cheng, 2002), where no clear difference was found between the chemical structures of flocs formed by PFS and $\mathrm{FeCl}_{3}$ using a fluorescence quenching method. The similar characterization results for the solid residues produced from FS and PFS resulted from the analogous products formed by Fe salt hydrolysis. The co-removed components from groundwater matrices might affect the hydrolysis process and impact the transformation behavior of Fe hydroxides.

\subsection{As k-edge EXAFS analysis for the coagulated solid residue}

The As molecular-level interface structure in the solid residue is important for evaluating As removal efficiency and transformation behavior in residue disposal, and consequently was investigated using XANES and EXAFS analysis (Fig. 8). LCF analysis showed that $\mathrm{As}(\mathrm{V})$ contributed $93 \%$ and $94 \%$ of As in the residue from FS and PFS (Fig. 8a), respectively. Thus, the primary As(III) in groundwater was effectively oxidized by $\mathrm{Ca}(\mathrm{ClO})_{2}$ during two-bucket system performance. The small
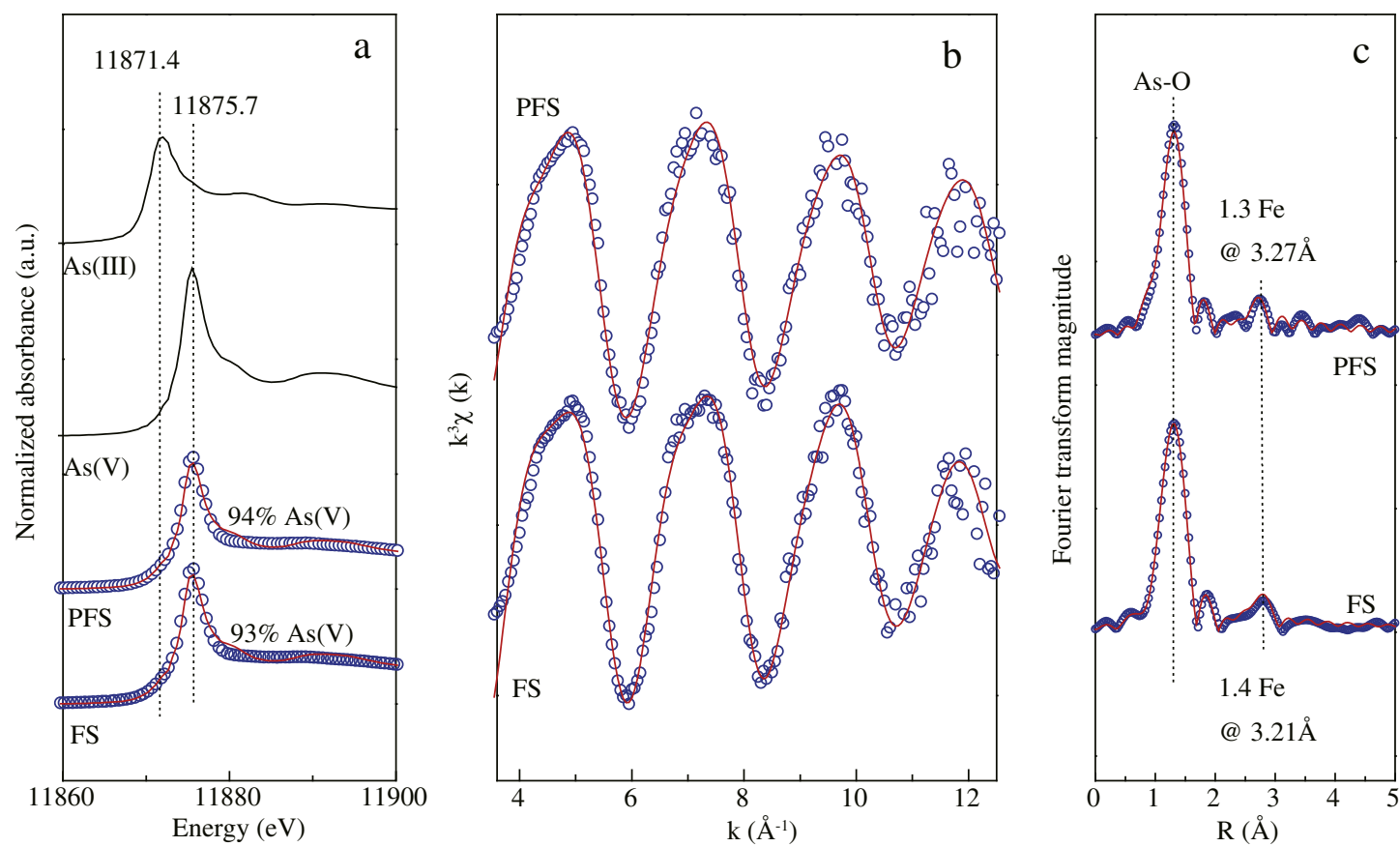

Fig. 8 - Arsenic k-edge extended X-ray absorption fine structure (EXAFS) data for groundwater coagulated solids with ferric sulfate (FS) and polyferric sulfate (PFS) (a) X-ray absorption near-edge structure (XANES) spectra with the percentages of As(III) by linear combination fit (LCF) fit; (b) $\mathbf{k}^{3}$-weighed EXAFS spectra; (c) their corresponding Fourier transform (FT) magnitude. Experimental and calculated curves are displayed as blue dotted and red solid lines, respectively. All fit parameters are detailed in Appendix A Table S6. 
amount of $\mathrm{As}(\mathrm{III})(6 \%-7 \%)$ is consistent with the field As speciation analysis, that occasionally showed that 4-8 $\mu \mathrm{g} / \mathrm{L}$ As(III) was left and subsequently retained on the Fe flocs in the sand layer.

The As k-edge EXAFS of the solid residue from groundwater was well fitted (Fig. 8b-c). The first peak was modeled with 4.1 and $3.9 \mathrm{O}$ atoms at a distance of $1.69 \AA$ for FS and PFS, respectively (Fig. 8c and Appendix A Table S7). These distances and coordination numbers correspond to a regular $\mathrm{AsO}_{4}$ tetrahedron (Jing et al., 2005, 2012). Twelve As-O-O triangular multiple scattering (MS) paths were implemented in the fit with distances at $3.04 \AA$ to $3.08 \AA$ for FS and PFS, respectively. This MS fitting result is in accordance with the MS distance (3.05 $\AA$ ) found for a co-precipitated sample with a $\mathrm{Fe} / \mathrm{As}(\mathrm{V})$ molar ratio of 4 at $\mathrm{pH} 8$ (Chen et al., 2009).

The second peak was attributed to 1.4 and $1.3 \mathrm{Fe}$ atoms with interatomic distance of $3.21 \AA$ and $3.27 \AA$ for FS and PFS, respectively (Fig. 8c and Appendix A Table S7). These fitted distances are identical to those estimated for $\mathrm{As}(\mathrm{V})$ bidentate binuclear complexes on ferrihydrite of $3.25 \pm 0.02 \AA$ (Waychunas et al., 1993). The As-Fe distance for FS and PFS was not consistent with the monodentate As-Fe distance of $3.60 \pm 0.03 \AA$ (Waychunas et al., 1993), and no coincidence was observed with the longer As-Fe distance (3.36 $\AA$ ) in scorodite (Chen et al., 2009). Thus, the As k-edge EXAFS fitting results indicated that the removed As formed bidentate binuclear complexes on the in situ formed Fh. The As inner-sphere adsorption complex is beneficial for As immobilization in the solid residue.

\subsection{Safety evaluation for the solid residue}

The remobilization of the adsorbed As on the solid residue is a crucial concern for groundwater treatment systems and ultimate landfill disposal. In both FS and PFS treatments, leachate from the produced residue generated using three leaching methods (Fig. 9) showed low concentrations of As (0.9 to $489 \mu \mathrm{g} / \mathrm{L}$ ). The leachate As was much lower than the US

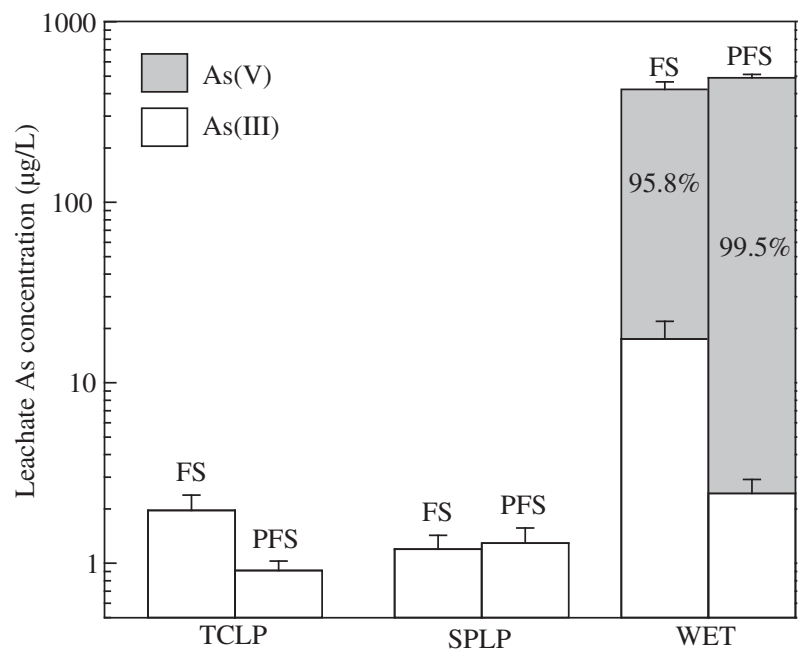

Fig. 9 - As leaching results from the coagulated solid residue using toxicity characteristic leaching procedure (TCLP), synthetic precipitation leaching procedure (SPLP), and California waste extraction test (WET). The percentages in WET columns show $\mathrm{As}(\mathrm{V})$ in the leachate As.
EPA's regulation of $5 \mathrm{mg} / \mathrm{L}$, indicating that the residue could be safely disposed as landfill.

For TCLP and SPLP, the leachate As was only 0.9-2.0 $\mu \mathrm{g} / \mathrm{L}$ from the coagulated residue for FS and PFS, three orders of magnitude lower than $5 \mathrm{mg} / \mathrm{L}$ (Fig. 9). Furthermore, the removed As in the coagulated residue is stable from the point of view that SPLP is used to mimic acid rain under environmental disposal anaerobic conditions (Clancy et al., 2013). In leachates from both TCLP and SPLP, only As(III) was observed, with no detection of As(V). The results are consistent with the finding that As(III) is much more weakly adsorbed than $\mathrm{As}(\mathrm{V})$ at the study $\mathrm{pH}(4.2-5)$ and subsequently is more easily released from Fe hydroxide (Mercer and Tobiason, 2008).

Cal WET tests promoted As release of $422 \mu \mathrm{g} / \mathrm{L}$ and $489 \mu \mathrm{g} / \mathrm{L}$ from residue for FS and PFS, respectively (Fig. 9). The leachate As level in WET is one order of magnitude higher than that in TCLP and SPLP because the citric acid in the procedure can strongly chelate $\mathrm{Fe}$ in $\mathrm{Fe}$ hydroxide and dissociate As to solution (Clancy et al., 2013). Nevertheless, the released As level was still an order of magnitude lower than the US EPA's regulation. The leachate As in WET was primarily in the form of $\mathrm{As}(\mathrm{V})$, at $95.8 \%$ for FS and $99.5 \%$ for PFS, respectively. This is because of the high content of $\mathrm{As}(\mathrm{V})$ adsorbed in the solid residue, as confirmed by the As k-edge XANES analysis.

The collected residual sludge in the sand layer was freeze-dried, and weighed $70.8 \mathrm{~g}$ for FS in 27 buckets and $62.9 \mathrm{~g}$ for PFS in 30 buckets up to five cycles. The smaller quantity of residue from PFS (2.6 g/18 L in one bucket) than FS ( $2.1 \mathrm{~g} / 18 \mathrm{~L}$ in one bucket) resulted from the lower dose of PFS than FS, suggesting that PFS is more appropriate for groundwater treatment given their similar As treatment efficiency in the two-bucket system. By using PFS to supply As-safe drinking water, assuming that $18 \mathrm{~L}$ is adequate for daily use in a family of four, it is estimated that $765 \mathrm{~g}$ residual solid per year could be generated, which is a small amount and could be disposed of safely in view of passing the leaching tests.

\subsection{Social acceptability assessment of the two-bucket treatment system}

Considering the cost of added chemicals only and $18 \mathrm{~L}$ drinking water per day for one family, the cost of As-safe water each year using the two-bucket system was calculated to be 17.5 CNY (USD 2.8) by FS and 3.3 CNY (USD 0.5) by PFS, respectively. The cost is acceptable for the local residents in Shanxi, China with a per capita net income of CNY 7154 in 2013 (Shanxi Statistical Bureau, 2014). Thus, from the aspects of As treatment efficiency, quantity of solid residue, and cost of the treated water, PFS provided better performance in the two-bucket system for groundwater treatment.

\section{Conclusions}

This study evaluated groundwater As removal using FS and PFS based on field coagulation experiments and characterized the removal mechanism, integrating macroscopic and microscopic techniques. More than 95\% of As (13.6-1067 $\mu \mathrm{g} / \mathrm{L})$ can be removed with a dose of $0.12 \mathrm{~g} / \mathrm{L}$ FS and $0.10 \mathrm{~g} / \mathrm{L}$ PFS, 
highlighting the important role of Fe/As ratios. The two-bucket system, combining coagulation and sand filtration, can supply $500 \mathrm{~L}$ of As-safe water $(<10 \mu \mathrm{g} / \mathrm{L})$ during five treatment cycles using FS and PFS. As k-edge XAFS analysis coupled with Fe $\mathrm{k}$-edge XANES indicated that the As removed by coagulation formed a bidentate binuclear complex on the freshly formed Fh predominant in the solid residue. Leaching tests demonstrated that the solid residue satisfied the EPA regulatory limit and can be disposed of safely. Finally, given its similar As treatment performance, PFS is superior to FS because of its much lower solid residue, lower cost, and easier settling during coagulation.

\section{Acknowledgments}

This work was supported by the Strategic Priority Research Program of the Chinese Academy of Sciences (No. XDB14020201), the National Natural Science Foundation of China (Nos. 41373123, 21337004), and the Research Center for Eco-Environmental Sciences, Chinese Academy of Sciences (No. YSW2013A01).

\section{Appendix A. Supplementary data}

Supplementary data to this article can be found online at http://dx.doi.org/10.1016/j.jes.2014.10.020.

\section{RE F E R E N C E S}

Chen, Y., Ahsan, H., 2004. Cancer burden from arsenic in drinking water in Bangladesh. Am. J. Public Health 94 (5), 741-744.

Chen, N., Jiang, D.T., Cutler, J., Kotzer, T., Jia, Y.F., Demopoulos, G.P., et al., 2009. Structural characterization of poorly-crystalline scorodite, iron(III)-arsenate co-precipitates and uranium mill neutralized raffinate solids using X-ray absorption fine structure spectroscopy. Geochim. Cosmochim. Acta 73 (11), 3260-3276.

Cheng, W.P., 2002. Comparison of hydrolysis/coagulation behavior of polymeric and monomeric iron coagulants in humic acid solution. Chemosphere 47 (9), 963-969.

Cheng, Z.Q., Van Geen, A., Jing, C.Y., Meng, X.G., Seddique, A., Ahmed, K.M., 2004. Performance of a household-level arsenic removal system during 4-month deployments in Bangladesh. Environ. Sci. Technol. 38 (12), 3442-3448.

Clancy, T.M., Hayes, K.F., Raskin, L., 2013. Arsenic waste management: a critical review of testing and disposal of arsenic-bearing solid wastes generated during arsenic removal from drinking water. Environ. Sci. Technol. 47 (19), 10799-10812.

Cui, J.L., Shi, J.B., Jiang, G.B., Jing, C.Y., 2013. Arsenic levels and speciation from ingestion exposures to biomarkers in Shanxi, China: implications for human health. Environ. Sci. Technol. 47 (10), 5419-5424.

Davis, C.C., Edwards, M., 2014. Coagulation with hydrolyzing metal salts: mechanisms and water quality impacts. Crit. Rev. Environ. Sci. Technol. 44 (4), 303-347.

Dodd, M.C., Vu, N.D., Ammann, A., Le, V.C., Kissner, R., Pham, H.V., et al., 2006. Kinetics and mechanistic aspects of As(III) oxidation by aqueous chlorine, chloramines, and ozone: relevance to drinking water treatment. Environ. Sci. Technol. 40 (10), 3285-3292.

Du, J.J., Jing, C.Y., Duan, J.M., Zhang, Y.L., Hu, S., 2014. Removal of arsenate with hydrous ferric oxide coprecipitation: effect of humic acid. J. Environ. Sci. 26 (2), 240-247.

Fan, M., Brown, R.C., Sung, S.W., Huang, C.P., Ong, S.K., van Leeuwen, J.H., 2003. Comparisons of polymeric and conventional coagulants in arsenic(V) removal. Water Environ. Res. 75 (4), 308-313.

Fendorf, S., Michael, H.A., van Geen, A., 2010. Spatial and temporal variations of groundwater arsenic in South and Southeast Asia. Science 328 (5982), 1123-1127.

Jia, Y.F., Xu, L.Y., Fang, Z., Demopoulos, G.P., 2006. Observation of surface precipitation of arsenate on ferrihydrite. Environ. Sci. Technol. 40 (10), 3248-3253.

Jing, C.Y., Liu, S.Q., Patel, M., Meng, X.G., 2005. Arsenic leachability in water treatment adsorbents. Environ. Sci. Technol. 39 (14), 5481-5487.

Jing, C.Y., Cui, J.L., Huang, Y.Y., Li, A.G., 2012. Fabrication, characterization, and application of a composite adsorbent for simultaneous removal of arsenic and fluoride. ACS Appl. Mater. Interfaces 4 (2), 714-720.

Liang, Z., Wang, Y.X., Zhou, Y., Liu, H., Wu, Z.B., 2009. Hydrolysis and coagulation behavior of polyferric sulfate and ferric sulfate. Water Sci. Technol. 59 (6), 1129-1135.

Lin, J.L., Huang, C., Chin, C.M., Pan, J.R., 2008. Coagulation dynamics of fractal flocs induced by enmeshment and electrostatic patch mechanisms. Water Res. 42 (17), 4457-4466.

Luo, T., Cui, J.L., Hu, S., Huang, Y.Y., Jing, C.Y., 2010. Arsenic removal and recovery from copper smelting wastewater using $\mathrm{TiO}_{2}$. Environ. Sci. Technol. 44 (23), 9094-9098.

Luo, T., Hu, S., Cui, J.L., Tian, H.X., Jing, C.Y., 2012. Comparison of arsenic geochemical evolution in the Datong Basin (Shanxi) and Hetao Basin (Inner Mongolia). China Appl. Geochem. 27 (12), 2315-2323.

Maiti, A., Basu, J.K., De, S., 2012. Experimental and kinetic modeling of $\mathrm{As}(\mathrm{V})$ and $\mathrm{As}(\mathrm{III})$ adsorption on treated laterite using synthetic and contaminated groundwater: effects of phosphate, silicate and carbonate ions. Chem. Eng. J. 191, 1-12.

Malinowski, E.R., 1978. Theory of error for target factor-analysis with applications to mass-spectrometry and nuclear magnetic-resonance spectrometry. Anal. Chim. Acta 103 (4), 339-354.

Meng, X.G., Bang, S., Korfiatis, G.P., 2000. Effects of silicate, sulfate, and carbonate on arsenic removal by ferric chloride. Water Res. 34 (4), 1255-1261.

Meng, X.G., Korfiatis, G.P., Christodoulatos, C., Bang, S., 2001. Treatment of arsenic in Bangladesh well water using a household co-precipitation and filtration system. Water Res. 35 (12), 2805-2810.

Mercer, K.L., Tobiason, J.E., 2008. Removal of arsenic from high ionic strength solutions: effects of ionic strength, $\mathrm{pH}$, and preformed versus in situ formed HFO. Environ. Sci. Technol. 42 (10), 3797-3802.

Michel, F.M., Ehm, L., Antao, S.M., Lee, P.L., Chupas, P.J., Liu, G., et al., 2007. The structure of ferrihydrite, a nanocrystalline material. Science 316 (5832), 1726-1729.

Mohan Chandrasekaran, V.R., Muthaiyan, I., Huang, P.C., Liu, M.Y., 2010. Using iron precipitants to remove arsenic from water: is it safe? Water Res. 44 (19), 5823-5827.

Rodriguez-Lado, L., Sun, G., Berg, M., Zhang, Q., Xue, H., Zheng, Q., et al., 2013. Groundwater arsenic contamination throughout China. Science 341 (6148), 866-868.

Shanxi Statistical Bureau, 2014. Per Capita Net Income of Farmers in Shanxi Reaches 7154 CNY in 2013, Shanxi.

Sorlini, S., Gialdini, F., 2010. Conventional oxidation treatments for the removal of arsenic with chlorine dioxide, hypochlorite, potassium permanganate and monochloramine. Water Res. 44 (19), 5653-5659. 
US EPA, 1992. Method 1311 Toxicity Characteristic Leaching Procedure U.S. Government Printing Office (Washington, DC.).

US EPA, 2003. Workshop on Managing Arsenic Risks to the Environment: Characterization of Waste, Chemistry, and Treatment and Disposal Proceedings and Summary Report.

Wasserman, G.A., Liu, X.H., Parvez, F., Ahsan, H., FactorLitvak, P., van Geen, A., et al., 2004. Water arsenic exposure and children's intellectual function in Araihazar, Bangladesh. Environ. Health Perspect. 112 (13), 1329-1333.

Waychunas, G.A., Rea, B.A., Fuller, C.C., Davis, J.A., 1993. Surface chemistry of ferrihydrite: part 1. EXAFS studies of the geometry of coprecipitated and adsorbed arsenate. Geochim. Cosmochim. Acta 57 (10), 2251-2269.

Webb, S.M., 2005. SIXpack: a graphical user interface for XAS analysis using IFEFFIT. Phys. Scr. T115, 1011-1014.

Zhao, Y.X., Gao, B.Y., Shon, H.K., Cao, B.C., Kim, J.H., 2011. Coagulation characteristics of titanium (Ti) salt coagulant compared with aluminum (Al) and iron (Fe) salts. J. Hazard. Mater. 185 (2-3), 1536-1542. 